\title{
The Role of Group Members in Facilitating Treatment
}

\author{
Mark H. Stone \\ School of Social Work, Aurora University, USA
}

Copyright $(2016$ by authors, all rights reserved. Authors agree that this article remains permanently open access under the terms of the Creative Commons Attribution License 4.0 International License

\begin{abstract}
The Experiencing Scales were applied to a small therapy group over fifteen sessions to determine the category levels of perception, emotion and insight from the expression of verbal interaction among all members. Analysis identified a gradual and positive increase in category levels, three periods of interaction describing group behavior, and measures of the quantity and quality of responses by individual members. The implications of these findings are discussed with a recommendation for further such analyses as a means of insight for therapists and group members leading to the possible generalizing of findings.
\end{abstract}

Keywords Experiencing Scales, Personal Work, Facilitative Statements, Main Actor

\section{Introduction}

During the process of psychotherapy, the responses made by therapists are considered to be critical in facilitating change (Hollon \& Beck [9], Yalom \& Leszcz [32]). Therapist responses should model supportive and facilitative behavior. Clients in group psychotherapy may also have an effect on each other (Westbrook \& Kirk [29]). Wolf \& Schwartz [31], Moreno [23], Hill [8] and Lutz et al. [20] among other theorists view the responses of group members to one another as an essential part of group treatment. Data regarding group members' behavior in the process of group psychotherapy is sparse, but their role in the presence of others has been recognized as important in the change process since early in the history of group treatment (Joyce et al. [12]. For example, Slavson [27] reported the increase in free association and responses in group treatment as well as the increased stimulus for transference experiences. He also noted similar psychological processes among members could facilitate reduction of guilt or anxiety, and facilitate self-disclosure.

Across writers (Hardy et al. [7], Norcross [24]) the therapist is consistently viewed as having the main responsibility for establishing a structure in which it is safe for members to take the risks necessary in the therapeutic process. Whitaker [30] noted that the group leader has responsibility for maintaining norms that make the group a medium for help, for recognizing and repairing errors and problems as they develop, and for using events that occur in the group for the benefit of group members. While using the group to evoke the associations, emotions, and experiences that facilitate therapeutic work, the therapist is responsible for managing the group's responses to the limitation of members, and to the negative or harmful manner in which some responses may be expressed (Slavson [27], Roth \& Fonagy [26]).

Interpersonal demands are presented by working in a group (Kanas [13], Lorentzen et al. [19]). Each member must cope with the behavior of others, react to them or withhold reaction, exercise compromise or restraint, attend to the participation of others, and expose herself or himself to the observation and response of others. The responses of members occur at various levels of insight and complexity, elicit information, form observations based of the group's interaction and those of individual members, make interpretive and confrontive responses considered to be the core of therapeutic work.

How to record and analyze and interpret group members' participations in therapy is difficult. A full record of comments and interaction is necessary. Especially important is how to analyze the comments and responses. A very systematic approach is required to record and classify their responses for analysis (Mellor-Clark \& Barkham [21], Hunsley \& Lee [10]).

Studies based on the direct observations of group members and their contributions to the therapeutic work of other members and the group as a whole may further inform the group psychotherapy process (Hunsley et al. [11], Montgomery [22]). This study investigated these matters by producing a complete recording of all sessions, and by applying a classificatory process by which to order the responses of group members, and to analyze them.

\section{Instrumentation}

The Experiencing Scales are based on the theoretical work of Rogers [25] and Gendlin [3] designed to assess characteristics of an individual's work in self-exploration 
and self-understanding during the process of psychotherapy. Ratings are made based upon the verbal expression of thoughts and emotions. Their concept of experiencing defines the qualities of an individual's ability to recognize, perceive, and accept his or her feelings and their personal meanings. Central to their concept of experiencing is the extent of personal awareness of subjective experience, and the manner in which subjective experience is used in thought (Greenberg \& Watson [6]; Goldman et al. [5]). Rogers's view of the process of psychotherapy is that it must provide the conditions which enable an individual to examine her or his perceptions, thoughts, and feelings in a manner that facilitates correction, adaptation, or change when appropriate. Awareness and acceptance are essential to the process (Yalom \& Leszcz,[32]; Feltham \& Horton [2]).

The Experiencing Scales utilized in this study were originally developed by Klein, Mathieu, Gendlin \& Kiesler [15] with the inclusion of the Therapist Experiencing Scales (Klein \& Mathieu-Coughlin [14]) so that the expressed verbal interaction of both parties in the psychotherapy process could be assessed.

The categories of the scales progress from limited self-reference to elaborated descriptive expression of perception, emotion, and their effects on behavior. The seven levels of the Experiencing Scales are rated on the manifest, verbally expressed content of the presumed thought processes of the speaker. The categories of the Experiencing Scales can be briefly described as follows:

At Category One, statements are impersonal in content. They may refer to events and circumstances in general, and to matters external to the process of psychotherapy. These statements often take place at the beginning or end of a session, and/or serve as a transition.

At Category Two, events the speaker has witnessed are described, or ideas personally relevant to the speaker are expressed. The speaker's own behavior, or that of others, may be described. While affect may be apparent to a listener, the speaker does not specifically articulate feelings. Statements at category two often provide the context and detail for further examination of experience.

At Category Three, feelings are expressed in response to a specific situation or event.

At Category Four, the primary focus of the speaker is an account of inner experience, rather than outer events. An individual's feelings, emotions, and patterns of experience are the focus.

Category Five involves the formation and articulation of a problem or hypothesis about the self, posed and explored from a stance of inner experience and feeling. Patterns of feeling and experience are the subject of examination and questioning.

At Category Six, the inner referent, or felt sense, present in the process of self-exploration is perceived to change. Aspects of self-awareness and self-understanding are changed and integrated.

At Category Seven, a sustained expansion of awareness is apparent, with continued movement from one inner referent to others.

A more detailed description and definition of the scale categories with examples of ratings can be found in training manuals by Klein, Mathieu, Gendlin \& Kiesler [15], Klein \& Mathieu-Coughlin [14], Beck, Dugo, Eng \& Lewis [1], and Lewis, Beck, Dugo \& Eng [18].

Although the Experiencing Scales have primarily been employed to study the differences between individuals by describing the most frequent or consistent mode of experiencing at which an individual patient works, these instruments were also designed to be sensitive to changes in the thought processes within a single session of psychotherapeutic work.

The application of the Experiencing Scales to group interaction required taking into account that statements are made by group members in response to one another, statements are made which focus on and respond to the personal work of another as well as statements of personal self-exploration. Described by Hill [8] as Patient and Therapist Role Taking, this behavior of sometimes taking either role during the course of interaction is considered by him to be an essential and requisite aspect of the process of group psychotherapy.

The Therapist Experiencing Scales include one scale directly parallel to the client scale, called the Patient Content Referent Scale (Klein, M. H. \& Mathieu-Coughlin, P. L. [14]). There is also a Therapist Manner Scale. Since the application of the Therapist Experiencing Scales to patients when they take the facilitative or therapeutic role with one another is a new context for use of the scale, but the Patient Content Referent Scale was used to rate facilitative statements made by group members to one another. The Patient Content Referent Scale is firmly based upon the 1969 version of the Client Experiencing Scales (Klein, Mathieu, Gendlin \& Kiesler [15]) about which there is a substantial body of research work.

For this study, a judgment was made regarding each statement about whether it was one of personal self-examination, or one reflecting on and responding to the work of another member. The percent of agreement for two raters' classification of group members' statements as personal work or as facilitative statements was $96 \%$. Statements focused on the self were then rated using the Client Experiencing Scale, and statements focused primarily on responding to another member were rated on the Therapist Experiencing Scale. The reliability of two raters' classification of statements with the Experiencing Scales using Cohen's kappa was 0.57.

\section{Sample}

In this study, the entire course of verbal interaction during all 15 session of a short-term psychotherapy group were recorded, transcribed, rated and analyzed by category as described above. The group sessions took place in a 
university outpatient clinic. The leaders embraced client-centered treatment strategies. All of the clients in the group had received individual therapy before entering group treatment. The six clients in the group ranged in age from 24 to 52. Three were male, and three were female. The two therapists were female. Duration of the group treatment was predetermined so all the participants began attending therapy knowing the group would meet for 15 sessions.

\section{Analysis}

Transcripts of the verbal interaction of each session were made from audiotapes, and every statement was rated. Each statement was classified as either a facilitative statement, (rated on the Therapist Experiencing Scale), or one of personal work (rated on the Client Experiencing Scale).

Data were summarized for each session. The number of statements at each level of the scale was calculated for both statements classified as personal work and rated on the Client Scale, and the statements classified as facilitative and rated on the Therapist Scale.

\section{Results}

The results of data analysis provide three focal points for appraising group dynamics; (1) the interaction process of the group over fifteen sessions according to the ratings of group members using the Experiencing Scales, (2) subsequent identification of three periods of therapeutic work in the course of these 15 sessions, and (3) the record of individual/personal work and facilitative statements of group members.

\subsection{Charting the Process of the Group over Fifteen Sessions}

The range of Experience Scale ratings goes from 1 to 7 , but client ratings only went as high as 6 . This latter category occurred infrequently and only in the last three sessions. The means for sessions 1 to 15 ranged from 1.95 to 3.49 with a total mean of 2.5 , SD 0.43 , median 2.3, and mode 2.2. Category 2 accounted for $48 \%$ of the categories with Categories 1 and 3 at $13 \%$ and $18 \%$ respectively.

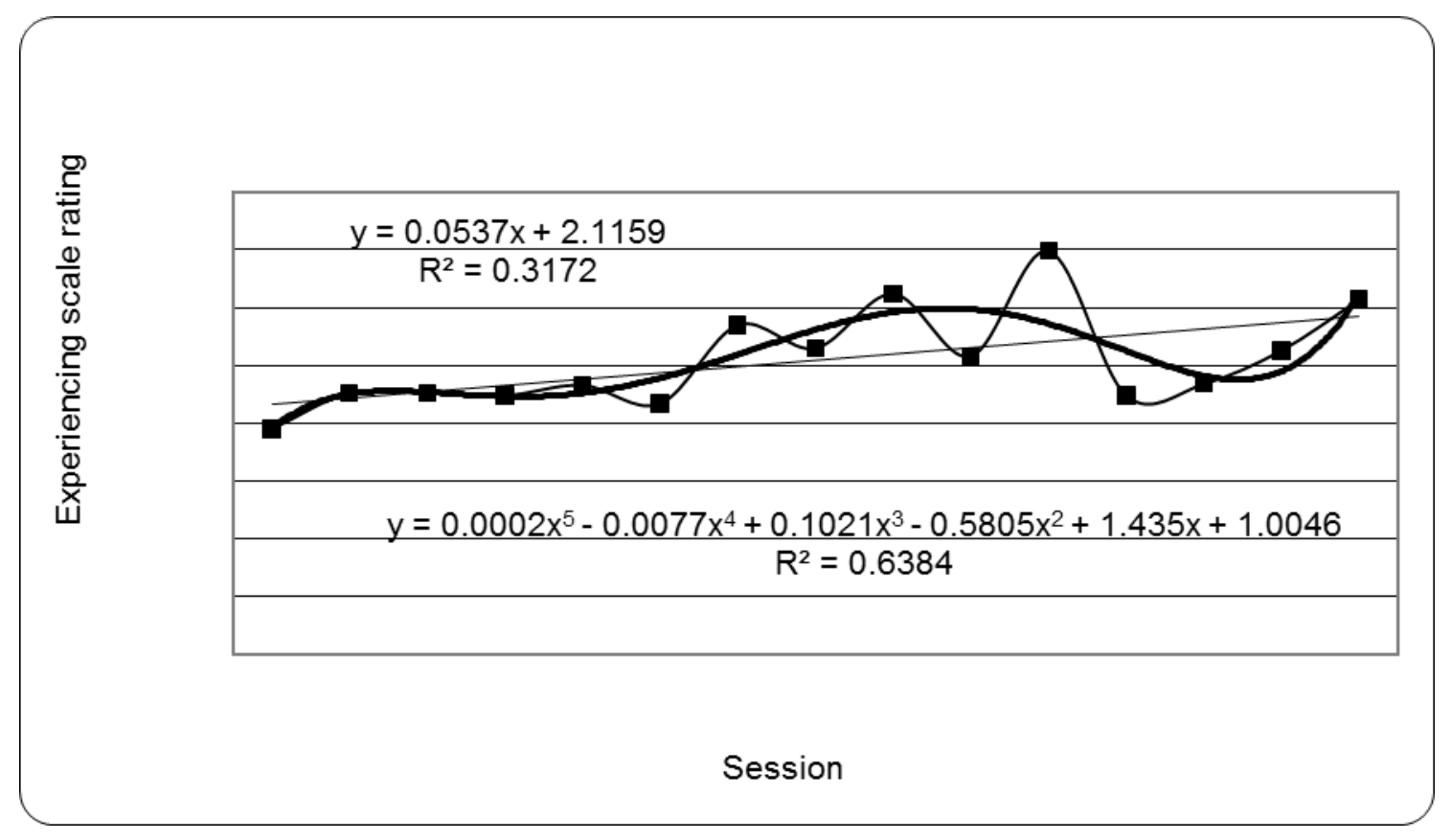

Figure 1. Average experience sale ratings 1-6 across sessions 1-15 


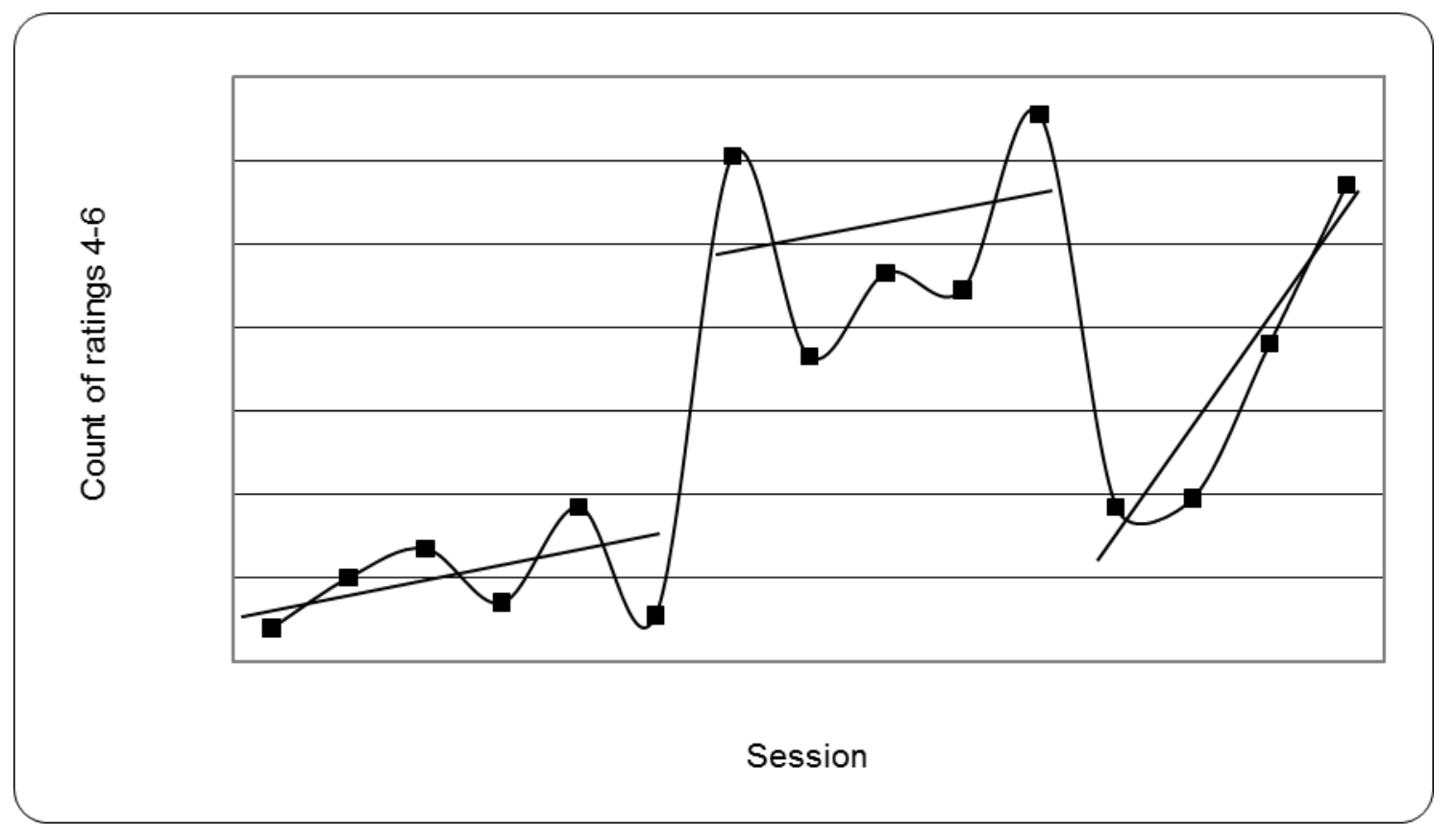

Figure 2. Number of statements by experience ratings $4-6$ across sessions $1-15$ with periods 1,2 , and 3 trend lines

Figure 1 is a graph constructed from the average scale ratings across each of the fifteen therapy sessions. The average rating increased from 1.95 for session 1 to 3.07 for session 15. A linear trend shows a gradual slope accounting for about $32 \%$ of the variance. Figure 1 also shows an undulating flow between the first and last session modeled by a $5^{\text {th }}$ degree polynomial curvilinear relationship which explains about $63 \%$ of the variance leaving about $37 \%$ of the variance not explained by this curvilinear model.

\subsection{Identifying Three Periods of Therapeutic Activity}

Figure 2 gives the number of statements by experience scale ratings 4-6 across sessions 1-15. These higher level ratings signify work or interaction within the group. Three periods were identified by inspection of Figure 2 . The initial period goes from session 1 through session 6 , the middle period from session 7 through 11, and the last period from session 12 through 15 . In period 1 work or interaction at Category 2 of the scales is the most frequent category for every group session except for one. The period 1 mean for all categories (1-6) was 2.20. The middle period of interaction is characterized by work at a higher category level. The period 2 mean was 2.94 for categories 1-6. Work at Category 5 of the Experiencing Scales plays a significant role in the group interaction for the first time during session 7 marking the beginning of the middle period. The mean for period 3 for categories 1-6 was 2.57.

Periods 1 and 2 have about the same slope with no statistical difference between the two slope coefficients. While these two slopes indicate a similar rate of increase in category rating the mean of the middle five sessions is considerably higher in the count of ratings 4-6. Period 3 shows a much steeper slope that was statistically significant from the previous two slopes with a sharp increase in the count of ratings 4-6 over the last four sessions.

The count of category 4-6 statements for Period 1 increased from 8 in session 1 to 37 by session 5 , but there was a noticeable drop to 11 statements in session 6 . The mean number of statements (4-6) for period 1 was 19.5. Period 2 ranged from 121 category statements in session 7 to 131 statements in session 11 with a noticeable drop in the number of statements for sessions 8,9 , and 10 . The mean number of statements for period 2 was 101.4. The period 2 mean showed an increase of 80 statements above the average for period 1. While each of these two periods showed variation, especially period 2 , there was an overall increase. Period 3 begins with a substantial drop from 131 category statements in session 11 to 37 statements in session 12 . Following a low count for sessions 12 and 13, there was an increase for the last two sessions. Period 3 ranged from a low count of 37 statements in session 12 to a final count of 114 statements for session 15 , and a mean of 66.5 statements at levels 4-6 for sessions in the third period.

The increase in mean therapeutic productivity using statement count from period 1 to period 2 is substantial with an increase from 19.5 to 101.4 or about five times greater. The period 3 mean of 66.5 is a decrease from the higher period 2 mean of 101.4. However, the rate of increase in productivity for the last two sessions makes this period distinctly different from periods 2 and 3 . In fact, the lowest count in period 3 (37) is equal to the highest count (37) for period 1 .

\subsection{Personal Work and Facilitative Statements}

Table 1 gives the number of personal work and facilitative statements across the 15 sessions by client. Bolden values 
indicate the highest client productivity within the session. The mean number of productivity statements per session was 216.7 with a standard deviation of 10.01 .

Table 1. Number of personal work and facilitative statements by group members across sessions 1-15 with the Main Actor in bold

\begin{tabular}{|c|c|c|c|c|c|c|c|}
\hline Session & G & B & J & P & D & M & Total \\
\hline & & & & & & & \\
\hline 1 & 38 & 30 & $\mathbf{4 5}$ & 6 & 25 & 29 & 173 \\
\hline 2 & 53 & 14 & $\mathbf{8 1}$ & 42 & 24 & 0 & 214 \\
\hline 3 & 47 & 6 & 36 & 10 & $\mathbf{1 0 4}$ & 62 & 265 \\
\hline 4 & 23 & 7 & 59 & $\mathbf{7 6}$ & 57 & 34 & 256 \\
\hline 5 & $\mathbf{1 0 2}$ & 56 & 0 & 15 & 7 & 46 & 226 \\
\hline 6 & $\mathbf{6 3}$ & 0 & 53 & 15 & 0 & 31 & 162 \\
\hline 7 & 0 & 22 & 17 & 24 & 17 & $\mathbf{1 2 9}$ & 209 \\
\hline 8 & 35 & 27 & 0 & 24 & $\mathbf{1 0 6}$ & 33 & 225 \\
\hline 9 & 46 & 28 & 0 & 46 & $\mathbf{5 8}$ & 0 & 178 \\
\hline 10 & $\mathbf{1 7 1}$ & 0 & 0 & 68 & 63 & 0 & 302 \\
\hline 11 & 40 & 17 & 0 & 0 & $\mathbf{1 1 1}$ & 0 & 168 \\
\hline 12 & 40 & $\mathbf{9 3}$ & $\mathbf{8 9}$ & 0 & 0 & 0 & 222 \\
\hline 13 & 39 & 21 & 53 & $\mathbf{8 0}$ & 20 & 0 & 213 \\
\hline 14 & 36 & $\mathbf{8 0}$ & 44 & 38 & 0 & 0 & 198 \\
\hline 15 & $\mathbf{1 0 3}$ & 31 & 0 & 40 & 66 & 0 & 240 \\
\hline Total & 836 & 432 & 477 & 484 & 658 & 364 & 3251 \\
\hline Lead & 4 & $1(1)$ & $2(1)$ & 2 & 4 & 1 & \\
\hline
\end{tabular}

Table 1 summarizes the data by each individual participant across time in the group using summaries of member participation in each period, and for the entire length of the group process. While descriptive in nature, some observations can be made about the nature of individual participation in the group process across time.

For sessions 1-11 there is clear identification of a singular most productive client indicated in bold. Shared productivity in number of statements is shown for two clients in session 12. For the three remaining sessions there is a dominantly productive client.

The initial session and sessions six, nine, and eleven indicate a lower count total in the number of work statements. During session one the members introduce themselves to one another, and engage for the first time. The nature of this process is different from a later focus on disclosure, expressed thought processes, and responses made to other members of the group. No conclusion from group dynamics can be drawn for the lower count in the other three sessions.

Most of the fifteen sessions are characterized by the "main actor" phenomena (Soldz, Budman, Demby, \& Feldman [28]). Member $G$ has a higher rate of participation than all the other participants, and such a member's personal work and disclosure may serve as part of the structure for processing the entire group experience during the session where members allow a "main actor" to occupy center stage. Interaction in some sessions shows a less dominant frequency for the main actor. This aspect of interaction may provide the framework for allowing personal work by other group members.

Differences in the rate of participation among the members in successive sessions can be observed. Member J shows a decreased rate of verbal interaction after period two, effectively becoming more of a listener until session 12 . This member's style of interaction is also reflected in the use of fewer statements rated at levels 4 to 6 of the Experiencing Scales. Members B, J, and P limit their verbal expressions of personal work during period 2. A higher proportion of their expressed thought during period 2 is in the form of facilitative statements. Member B interacts at an increased rate in period 3, compared to his style in periods 1 and 2 .

Individual differences can also be observed in the rate of participation across the whole length of the group sessions. Members $G$ and $D$ speak most often and the total participation levels of members $\mathrm{B}, \mathrm{J}$, and $\mathrm{P}$ are almost equal (member $\mathrm{M}$ left the group in session 9).

While the group level process appears to determine aspects of the interaction in a way that characterizes the behavior of all members, the process also allows variance in individual performances and style. The manner in which the group works, the level, and the type of therapeutic work taking place among members appears to be a developmental process accomplished through group member interaction. However, individual members responded differently in sessions. The group level process determines significant aspects of work in the group, but allows an array of individual responses. Not all aspects of interaction can be coded using the experiencing scales.

\section{Discussion}

Members use facilitative behavior rather gradually during the initial period of interaction. The number of facilitative statements during session 1 was 36 and 37 in session 2, but the ability to respond to each other increased from about session 3. The number of facilitative statements made by members reaches a peak session 7, the point chosen retrospectively to mark the beginning of the second period of interaction. The increased frequency of facultative statements occurs as the group first achieves a higher level of therapeutic work which defines period 2 .

The average number of facilitative statements per session is 60 in the first period of interaction, and about 80 per session during periods 2 and 3. Facilitative statements account for about $25 \%$ of the verbal interaction of members, and personal therapeutic work accounts for about $75 \%$ of the statements. Members contribute consistently to the task of therapeutic intervention within the group as a whole, yet remain primarily focused on their individual work in the patient/client role.

\section{Implications for Further Study}

1. Three periods of interaction were defined based upon 
the mean Experience Scale ratings per session and confirmed by the count or number of statements per session rated at experiencing scale levels $4-6$. These are descriptive of this group and not generalizable. However, group movement through sessions may consist of stages in which members gain understanding and facilitate progress. They move from lower category levels in the initial sessions to higher ones in later sessions. The exact parameters are yet to be determined.

2. The level of therapeutic work measured by the Experiencing Scales increases across the fifteen sessions with the highest levels achieved in period 2 . We might ascribe introductory, work, and closing as the labels for the three stages for this group, but this may not be true in general depending upon length of total sessions, number of members, and the personal attributes of individual members.

3. Within each of the three periods there appeared a linear trend with increasing slope confirming a gradual increase overall in level of category in the Experiencing Scales. The number of statements at higher levels of therapeutic work increased with period 3 having the greatest range in number of such statements per session. The second period of interaction is defined by a consistently larger number of statements at higher levels.

4. As interaction within the group progressed, personal work was characterized by the capacity of the group to allow primary focus on a member who can be identified as "most productive" during that session. Across sessions this focus was shared with different members filling the role from session to session.

5. Individual members differ in their rate of participation. Members show differences which characterize their mode of interaction across time as a whole, but also show the capacity for differences across times, i.e. a member may become a listener during some sessions and appear more comfortable to work at different points in time.

6. The group members contributed consistently to the task of therapeutic response and intervention in the group. About one-quarter of their statements facilitate the work of other members, and three-quarters of their statements focused on personal therapeutic work.

7. The work of record-keeping for the group is no small task. Recording, transcribing and determining category levels is time consuming. While not possible for all groups it may prove valuable for group therapists to regularly conduct such a study with certain groups or for certain occasions. Only by assembling a data base of such record keeping can we validate findings. Such work has merit for their therapists and for the clients.

\section{REFERENCES}

[1] Beck, A. P., Dugo, J. M., Eng, A.M., \& Lewis, C. M. (1986). The search for phases on group development: Designing process analysis measures of group interaction. In L. S. Greenberg, \& W. M. Pinsof (Eds.). The psychotherapeutic process: A research handbook (pp. 615-705). New York: Guilford Press.

[2] Feltham, C. \& Horton, I. (2006). Handbook of Counselling and Psychotherapy. London: Sage.

[3] Gendlin, E. T. (1962). Experiencing and the creation of meaning. New York: The Free Press of Glencoe.

[4] Gendlin, E. T., \& Tomlinson, T. M. (1967). The process conception and its measurement. In C. R. Rogers, E. Gendlin, D. Kiesler, \& C. Truax (Eds.). The therapeutic relationship and its impact: A study of psychotherapy with schizophrenics (pp. 109-131). Madison: University of Wisconsin Press.

[5] Goldman, R., Greenberg, L. \& Angus, L. (2006). The effects of adding emotion-focused interventions to the therapeutic relationship in the treatment of depression. Psychotherapy Research 16, 537-549.

[6] Greenberg, L. \& Watson, C. (1998). Experiential therapy of depression: differential effects of client-centered relationship conditions and process experiential interventions. Psychotherapy-Research 8, 210-224.

[7] Hardy, G., Stiles, W., Barkham, W. \& Startup, M. (1998). Therapist responsiveness to client interpersonal styles during time-limited treatments for depression. Journal of Consulting and Clinical Psychology 66, 304-312.

[8] Hill, W. F. (1965). Hill interaction matrix. Los Angeles: University of California Press.

[9] Hollon, S. \& Beck, A. (2004). Cognitive and cognitive behavioral therapies. In M. Lambert (Ed.) Handbook of Psychotherapy and Behavior Change. pp. 447-492. Wiley: New York.

[10] Hunsley, J. \& Lee, J. (2007). Research-informed benchmarks for psychological treatments: efficacy studies, effectiveness studies, and beyond. Professional Psychology: Research and Practice 38, 21-33.

[11] Hunsley, J., Aubry, T., Verstervelt, C. \& Vito, C. (1999). Comparing therapist and client perspectives on reasons for psychotherapy termination. Psychotherapy 36, 380-388.

[12] Joyce, A., Piper, W. \& Ogrodniczuk, J. (2007). Therapeutic Alliance and Cohesion Variables as Predictors of Outcome in Short-Term Group Psychotherapy. International Journal of Group Psychotherapy 57 (3), 269-97.

[13] Kanas, N. (2005) "Group Therapy for Patients with Chronic Trauma-Related Stress Disorders." International Journal of Group Psychotherapy, 55 (1), 161-6

[14] Klein, M. H., \& Mathieu-Coughlin, P. L. (1986). The experiencing scales. In L. S. Greenberg, \& W. M. Pinsof (Eds.). The psychotherapeutic process: A research handbook (pp. 21-71). New York: Guilford Press.

[15] Klein, M. H., Mathieu-Coughlin, P. L., Gendlin, E. T., \& Kiesler, D. J. (1969). The experiencing scale: A research and training manual. Madison, WI: Wisconsin Psychiatric Institute.

[16] Leichsenring, F. \& Leibing, E. (2003). The effectiveness of psychodynamic therapy and cognitive behavior therapy in the treatment of personality disorders: a meta-analysis. American Journal of Psychiatry 160, 1223-1232. 
[17] Leichsenring, F. (2001). Comparative effects of short-term psychodynamic psychotherapy and cognitive-behavioral therapy in depression: a meta-analytic approach. Clinical Psychology Review 21, 401-419.

[18] Lewis, C. M., Beck, A. P., Dugo, J. M., \& Eng, A.M. (2000) The group development process analysis measures. In A. P. Beck, \& C. M. Lewis (Eds.). The process of group psychotherapy: Systems for analyzing change (pp. 221-262). American Psychological Association. Washington DC.

[19] Lorentzen, S., Bogwald, K. \& Hoglend, P. (2002) "Change during and after long-term analytic group psychotherapy." International Journal of Group Psychotherapy. 52 (3), 419-30

[20] Lutz, W., Leon, S. Martinovich, Z., Lyons, J. \& Stiles, W. (2007). Therapist effects and therapist performance clusters in outpatient psychotherapy. Journal of Counseling Psychology 54, 32-39.

[21] Mellor-Clark, J. \& Barkham, M. (2006). Quality evaluation: methods, measures and meaning. In Handbook of Counselling and Psychotherapy. (C. Feltham and I. Horton, Eds.), pp. 207-224. London: Sage.

[22] Montgomery, C. (2002). Advances in Psychiatric Treatment. 8 (1): 34-41. doi:10.1192/apt.8.1.34

[23] Moreno,J. L. (1963). Scientific foundations of group psychotherapy. In M. Rosenbaum, \& M. Berger (Eds.), Group psychotherapy and group function: Selected readings (pp. 315-322. New York: Basic Books.
[24] Norcross, J. (2002). Psychotherapy Relationships that Work: Therapist Contributions and Responsiveness to Patient Needs. New York: Oxford University Press.

[25] Rogers, C. R. (1958). A process conception of psychotherapy. American Psychologist, 13, 142-149.

[26] Roth, A. \& Fonagy, P. (2004). What Works For Whom? A Critical Review of Psychotherapy Research. New York: Guilford Publications

[27] Slavson, S.R. (1964) A textbook in analytic group psychotherapy. New York: International Universities Press.

[28] Soldz, S., Budman, S. H., Demby, A., \& Feldman, M. (1992). The relationship between main actor's behaviors and treatment outcome in group psychotherapy. Psychotherapy Research, 2, 52-62.

[29] Westbrook, D. \& Kirk, J. (2005). The clinical effectiveness of cognitive behavior therapy: outcome for a large sample of adults treated in routine practice. Behavior Research and Therapy 43, 1243-1261.

[30] Whitaker, D. S. (1985). Using groups to help people. London: Kegan Paul.

[31] Wolf, A. \& Schwartz, E. K. (1959). Psychoanalysis in groups: The role of values. American Journal of Psychoanalysis, 19, 37-52.

[32] Yalom, I. \& Leszcz, M. (2005) The Theory and Practice of Group Psychotherapy, 5th edition, New York: Basic Books 